\title{
Función y valor documental de los enlaces semánticos en la prensa española (2002-2016)
}

Dr. Bernardino J. Cebrián Enrique | dcebrian@uchceu.es Universidad Cardenal Herrera CEU

Dra.Paz Orero|mpaz@rtvv.es

Institut Valencià de Cultura - RTVV

Palabras clave

hipertexto, enlaces semánticos, documentación periodística, prensa, periodismo digital Sumario

1. Introducción. 2. Método. 3. Resultado y discusión. 4. Conclusiones 5. Bibliografía. 6. Notas 7

Financiación

\section{Resumen}

Esta investigación aborda las características y valor documentales de los enlaces semánticos en la prensa española de 2002 a 2016. Se analizan los enlaces integrados en el relato de las noticias de portada para examinar la riqueza de las fuentes de destino y las funciones documentales que cumplen.

Se parte, entre otras, de dos

hipótesis: la madurez de la prensa digital se traduce en un incremento de enlaces a recursos externos y en el cumplimiento de las funciones informativas clásicas de la documentación periodística.

El análisis de contenido se aplica a 4830 enlaces semánticos incluidos en el relato informativo de 4620 noticias de portada, procedentes de los tres diarios nacionales y los tres valencianos de mayor audiencia en Internet: El País, El Mundo, El Confidencial, Las Provincias, Levante-EMV y Valencia Plaza.

Los enlaces internos son los mayoritarios, aunque en menor grado en los medios nativos digitales. Se confirma la presencia de las funciones informativas clásicas. La función completiva es la predominante. La función crítico-verificadora destaca en los medios nativos, tiene valores equilibrados en los diarios nacionales tradicionales y es baja en los locales con edición en papel. La función informativa propia alcanza valores altos, pero se enlaza sobre todo a repositorios.

\section{Cómo citar este texto:}

Bernardino J. Cebrián Enrique y Paz Orero (2017): "Función y valor documental de los enlaces semánticos en la prensa española (2002-2016)", en Miguel Hernández Communication Journal, nº, pp. 489 a 519. Universidad Miguel Hernández, UMH (ElcheAlicante). Recuperado el _ de mhjournal.org] de 20_ de: @ink del artículo en 


\section{Function and documentary value of semantic links in the Spanish press (2002-2016)}

Dr. Bernardino J. Cebrián Enrique | dcebrian@uchceu.es Universidad Cardenal Herrera CEU

Dra.Paz Orero|mpaz@rtvv.es Institut Valencià de Cultura - RTVV

\section{Keywords}

hypertext, semantic links, journalistic documentation, press, digital journalism Summary

1. Introduction. 2. Method. 3. Result and discussion. 4. Conclusions 5. Bibliography. 6. Notes 7. Financing

\section{Abstract}

This research addresses the characteristics and documentary value of semantic links in the Spanish press from 2002 to 2016. The integrated links in the cover news story are analyzed to examine the richness of the destination sources and the documentary functions they fulfill.

It is based, among others, on two hypotheses: the maturity of the digital press translates into an increase in links to external resources and in the fulfillment of the classic informative functions of journalistic documentation.

The content analysis is applied to 4830 semantic links included in the informative story of 4620 front-page news, from the three national newspapers and the three Valencian ones with the highest Internet audience: El País, El Mundo, El Confidencial, Las Provincias, Levante -EMV and Valencia Plaza.

Internal links are the majority, although to a lesser degree in digital native media. The presence of classical informational functions is confirmed. The completive function is the predominant one. The critical-verifying function stands out in the native media, has balanced values in traditional national newspapers and is low in the premises with paper edition. The informative function itself reaches high values, but is linked above all to repositories.

\section{How to cite this text:}

Bernardino J. Cebrián Enrique and Paz Orero (2017): "Function and documentary value of semantic links in the Spanish press (2002-2016)", en Miguel Hernández Communication Journal, no8, pp. 489 to 519, Universidad Miguel Hernández, UMH (Elche-Alicante). Accessed 20 _ in: [paper link in mhjournal.org] 


\section{Introducción}

\subsection{Justificación}

La documentación periodística resulta esencial en el quehacer informativo. Los periodistas necesitan documentarse para poder informar con rigor y veracidad. Esta actividad, presente tanto en las etapas preparatorias y de previsión periodística como en la elaboración de los contenidos, puede desarrollar al máximo su potencial en el escenario comunicativo digital y en su herramienta fundamental: internet.

Elementos propios del ciberperiodismo como la hipertextualidad, interactividad, multimedialidad, personalización, actualización continua y la llamada memoria o documentación (García de Torres y Pou, 2003; Abadal y Guallar, 2010) favorecen enormemente el manejo de las fuentes informativas.

El hipertexto, mediante la vinculación de piezas con entidad propia, logra la construcción de un discurso con múltiples trayectorias y niveles de hondura que cada lector despliega según su criterio y necesidad. En el caso de la prensa digital, la hipertextualidad o hipermedialidad es una herramienta magnífica para conectar fragmentos, piezas o documentos informativos -ajenos y propios- y poner en valor los recursos de calidad de los profesionales y los fondos de los servicios de documentación de los medios de comunicación. El uso de los vínculos es una muestra cualitativa y de credibilidad de la información periodística difundida por los medios de comunicación. "Gracias a esta estructura discursiva hipertextual y a la profundidad relacional que promueve, los periodistas tienen la oportunidad de ofrecer una explicación completa y coherente entre los hechos sucedidos y la actualidad" (Larrondo, 2005: 157).

Por ello, el proceso de revisión de fuentes documentales que ha utilizado el periodista para la elaboración del producto informativo digital puede traspasar la tarea individual y sugerirse al lector ofreciendo contextualización, precedentes del hecho noticioso o incluso una selección de recomendaciones 
pertinentes de contenido adicional de la red que enriquezcan y eviten la superficialidad y simplificación de las noticias frente a la saturación informativa, las pseudofuentes, la heterogeneidad caótica y la desinformación, aspectos inherentes a internet. "La capacidad para hiperenlazar documentos de toda índole, actuales o retrospectivos, para ofrecer diferentes niveles de lectura y posibilitar una información lo más completa y selectiva posible, concede al periodismo digital un clarísimo valor documental" (Rubio Lacoba, 2007: 31).

A pesar de la importancia teórica y práctica del hipertexto y de la numerosa bibliografía sobre este rasgo esencial de la web y del discurso digital, no abundan los estudios empíricos sobre el grado de aplicación de los hipervínculos semánticos en la prensa española (Pérez Marco, 2003; Salaverría, Cores, Díaz Noci, Meso y Larrondo, 2004; Diezhandino, 2008; Fondevila Gascón, 2011 y 2013; Arias Robles, 2015). Las investigaciones son valiosos estudios de períodos puntuales que concluyen que la revolución vaticinada por la teoría del hipertexto no se ha cumplido en la práctica periodística y que el empleo de la hipertextualidad no ha alcanzado las expectativas enunciadas por la literatura científica para los medios de comunicación. Estos trabajos previos constatan que, tras una lenta adaptación, la utilización creciente de los enlaces es aún insuficiente y adolece de diversas carencias (Arias Robles, 2015).

Después de dos décadas de la aparición de las primeras ediciones digitales españolas, esta investigación aporta un estudio longitudinal retrospectivo (2002-2016) que incorpora criterios de la documentación, una disciplina habitualmente desatendida en los estudios sobre periodismo digital. Los resultados que se obtienen invitan a redescubrir el valor del hipertexto y su utilidad documental y abren caminos para innovar en los próximos años.

\subsection{Objetivo}

Este trabajo pretende examinar en el tiempo el valor documental del hipertexto semántico integrado en el relato informativo de las noticias de portada de la prensa española. Se busca determinar el uso y la transformación 
desde el año 2002 al 2016 e indagar en su clase, destino y singularidad según las características de las diversas cabeceras. Concretamente, se analiza el grado de utilización de fuentes documentales externas y la diversidad de éstas como destino de los enlaces, por un lado; se examina con detalle los enlaces a productos periodísticos documentales, por otro; y se estudian las funciones informativas documentales que cumplen esos hipervínculos, por último.

\subsection{Hipótesis}

1) El buen periodismo se caracteriza por la consulta de fuentes múltiples $y$ variadas. En el caso de las fuentes documentales, se espera observar una evolución en este sentido, de un estadio inicial con enlaces fundamentalmente a recursos propios o internos a un momento como el actual en el que se espera un mayor peso de los enlaces a fuentes externas.

2) Asimismo, en consonancia con el desarrollo de la propia red, se prevé confirmar una diversificación de los tipos de enlaces externos, de modo que no sólo se remite a páginas web de instituciones y de otros medios de comunicación, sino también a contenidos alojados en redes sociales y blogs.

3) Debido a la situación precaria de los departamentos de documentación en los medios españoles (Orero y Cebrián, 2014), esperamos detectar un empobrecimiento en lo referente a enlaces a productos periodísticos documentales (cronologías, especiales, perfiles, etc.). Tradicionalmente, esas piezas las elaboraban los documentalistas.

4) Desde los inicios del periodismo la documentación ha cumplido unas funciones informativas que contribuyen al conocimiento de la realidad y su comunicación. Mantenemos la hipótesis de que los enlaces que observamos en los relatos de los medios digitales continúan esa tradición. La esencia del periodismo exige la presencia de las funciones informativas clásicas de la documentación periodística. 


\section{Método}

El objetivo de la investigación no podría llevarse a cabo sin el examen y disección de los mensajes periodísticos publicados a lo largo del tiempo. No obstante, frente a otros métodos de análisis de texto, se ha elegido el de contenido porque está fundamentado en el método científico, permite describir cuantitativa y sistemáticamente los rasgos formales y de contenido de gran cantidad de piezas informativas, y la validez de las deducciones se sustenta en los procedimientos previos (Sánchez Aranda, 2005; Igartura Perosanz, 2006).

\subsection{Universo y muestra}

El universo objeto de estudio lo constituye el conjunto de cabeceras digitales españolas. La imposibilidad de abarcar ese universo empuja a seleccionar una muestra representativa y consistente, tras aplicar cuatro criterios objetivos: estudio tanto de diarios nativos digitales como de otros que mantienen versión en papel; inclusión no sólo de medios nacionales sino también locales; liderazgo de audiencia; y heterogeneidad en la propiedad empresarial. La muestra resultante está constituida por las 6 cabeceras siguientes: El País, El Mundo, El Confidencial, Las Provincias, Levante-EMV y Valencia Plaza.

A la hora de escoger las cabeceras locales, nos hemos centrado en el ámbito de

la Comunidad Valenciana, tras asegurar la representatividad. La muestra contempla tanto diarios digitales como otros que mantienen una versión en papel. Prioriza aquellos periódicos con mayor número de usuarios únicos en su ámbito de edición, según la certificación oficial de ComScore en 2015. Refleja la heterogeneidad en la propiedad empresarial: lasprovincias.es y levante-emv.com son representativos de los grupos de prensa regional Vocento y Prensa Ibérica, y valenciaplaza.com es un caso ilustrativo de financiación autóctona.

Una vez determinada la muestra de cabeceras, debido a la enorme producción de información que estos medios generan diariamente, se establece la selección 
de las piezas informativas que se someterán al análisis de contenido. En este paso, se atiende a otros cuatro criterios.

En primer lugar, se escogen los contenidos publicados en portada. Esta ubicación se suele otorgar a las informaciones tratadas con más amplitud y consideradas principales, lo que se traduce en un tratamiento hipertextual más amplio y rico. En segundo lugar, se selecciona la versión de la franja horaria de la tarde, pues asegura mayor elaboración y, en el caso de los medios que editan en papel, distanciamiento de los contenidos que provienen del volcado de la edición impresa efectuado en la madrugada.

El tercer criterio fija la fecha de publicación. Para dar el máximo alcance a este estudio longitudinal retrospectivo, se ha tenido en cuenta tanto la antigüedad de cada cabecera en la red como la disponibilidad de sus hemerotecas en abierto. Debido a estos dos condicionantes, el período temporal del estudio no es idéntico en todos los diarios de la muestra, ya que viene determinado por la consulta de los fondos a través de la navegación cronológica. Esta realidad origina que el período temporal de análisis varíe según las cabeceras. La restricción de consulta se ha aprovechado para vincular medios con rasgos comunes con el propósito de fijar tramos idénticos de análisis y poder comparar resultados de manera más rigurosa, quedando establecidos las siguientes parejas: elpais.com y elmundo.es (2002-2016), lasprovincias.es y levante.com (2008-2016), y elconfidencial.com y valenciaplaza.com (20102015).

Una vez establecidos los lapsos temporales, la ubicación en portada y franja horaria de publicación, se determina la selección final de la muestra de las piezas informativas de portada correspondientes a dichos periodos de publicación en los seis medios objeto de estudio, a través de un muestreo probabilístico aleatorio por conglomerados polietápico. En una primera fase se selecciona el conglomerado de mes y, a través de un muestreo aleatorio sistemático $(\mathrm{n}+3)$, se obtienen los meses de enero, abril, julio y octubre. A continuación, se toman como conglomerados las semanas (de lunes a 
domingo) de cada mes y se aplica, una vez más, un muestreo aleatorio sistemático en cada uno de los meses (n-1). Las semanas escogidas son la cuarta para enero, la tercera para abril, la segunda para julio y la primera para el mes octubre. Finalmente, se aplica un muestreo aleatorio simple para la determinación de las piezas informativas a analizar: tres noticias al azar de las que aparecen publicadas en la portada del diario en cada uno de los días escogidos en la primera etapa de muestreo.

En consecuencia, el análisis se efectúa sobre 21 piezas informativas por semana, en los intervalos cronológicos anteriormente detallados por grupos de cabeceras, lo que supone un total de 4620 piezas informativas como muestra objeto de análisis.

\subsection{Representatividad de la muestra}

Una vez establecida la muestra, se procede a estimar si tiene un tamaño adecuado y, en consecuencia, resulta representativa, válida y confiable. Por ello, se aplica la fórmula reservada a las poblaciones infinitas (Murray y Larry, 2009) ya que en todos los diarios objeto de análisis la población es desconocida -no se puede precisar el número de unidades de observación que la integran, aunque supera los 100.000:

$\mathrm{n}=\left(\mathrm{Z}^{\wedge} 2^{*} \mathrm{p} *(1-\mathrm{p})\right) / \mathrm{e}^{\wedge} 2$

Donde:

$$
\begin{aligned}
& \mathrm{n}=\text { tamaño de la muestra } \\
& \mathrm{Z}=\text { nivel de confianza }(1,96) \\
& \mathrm{p}=\text { posibilidad de éxito }(0,5) \\
& 1-\mathrm{p}=\text { posibilidad de fracaso }(0,5) \\
& \mathrm{e}=\text { margen de error máximo }
\end{aligned}
$$

Aunque todos los diarios objeto de análisis son universos infinitos, la estimación de la muestra se realiza por cabeceras, es decir, de manera 
individualizada, debido a que la cantidad de información disponible en las hemerotecas webs es diversa y la muestra se debe adaptar inevitablemente a esas posibilidades reales que ofrecen los archivos digitales. Por ello, cada periódico representa un universo separado. En consecuencia, como el número de unidades de muestra es proporcional al intervalo temporal accesible, hay ligeras variaciones en el error máximo admitido. En aquellas cabeceras con más posibilidades de años de consulta retrospectiva, el índice de aceptable se ha reducido.

Tabla 1: Ficha técnica de la muestra

\begin{tabular}{|c|c|c|c|c|c|c|}
\hline & $\begin{array}{c}\text { Nivel de } \\
\text { confianza }\end{array}$ & Distribución & $\begin{array}{c}\text { Margen } \\
\text { de error }\end{array}$ & $\begin{array}{c}\text { Días de } \\
\text { muestra }\end{array}$ & $\begin{array}{c}\text { Unidades } \\
\text { de } \\
\text { muestra }\end{array}$ & $\begin{array}{c}\text { Alcance } \\
\text { recomendado } \\
\text { de muestra }\end{array}$ \\
\hline elpais.com & $95 \%$ & $50 \%$ & $+/-3 \%$ & 392 & 1155 & 1067 \\
\hline elmundo.es & $95 \%$ & $50 \%$ & $+/-3 \%$ & 392 & 1155 & 1067 \\
\hline lasprovincias.es & $95 \%$ & $50 \%$ & $+/-4 \%$ & 224 & 672 & 600 \\
\hline levante-emv.com & $95 \%$ & $50 \%$ & $+/-4 \%$ & 224 & 672 & 600 \\
\hline elconfidencial.com & $95 \%$ & $50 \%$ & $+/-5 \%$ & 168 & 504 & 384 \\
\hline valenciaplaza.com & $95 \%$ & $50 \%$ & $+/-5 \%$ & 154 & 462 & 384 \\
\hline TOTAL & & & & & 4620 & 4102 \\
\hline
\end{tabular}

En conclusión, la muestra establecida para cada diario cumple el tamaño exigible y resulta, por tanto, válida, representativa y significativa.

\subsection{Ficha de análisis}

Ante la inexistencia de propuestas metodológicas previas que se ajustaran de forma plena a todos los objetivos, se procede al diseño de una ficha de análisis propia, a partir de la inclusión de distintas variables procedentes de las aportaciones de destacados investigadores del hipertexto y de la documentación periodística (Galdón, 1994 y 2002; Codina, 2003; Rubio Lacoba, 2007; Diezhandino, 2008; Guallar, 2011; Fondevila Gascón, 2014; Arias Robles, 2015). 
Por una parte, se recogen 4 elementos identificativos:

i) Datos identificativos:

(1) Número de identificación del hipervínculo.

(2) Número de identificación de la pieza informativa de la que procede.

(3) Titular periodístico de la información de procedencia.

(4) Fecha de publicación de la información de procedencia.

Por otra, se analizan las características que informan sobre el valor y función documentales del nodo de destino del enlace que se está analizando:

i) Destino del enlace: interno o externo.

ii) Categoría documental del nodo de destino:

(1) Género periodístico o documental

(2) Tipología de destino:
(a) Propio medio
(b) $\mathrm{B} \log$
(c) Medio ajeno
(d) Medio del grupo
(e) Redes sociales
(f) Web institucional
(g) Web personal
(h) Otras

iii) Género documental o producto periodístico documental del nodo de destino basado en las aportaciones de Rubio Lacoba (2007) y Guallar (2011) que actualizan para el periodismo digital la tipología clásica de piezas de carácter documental (Galdón, 1994) que complementan a las de actualidad. Los valores para la codificación son:

(1) Cronología

(2) Efeméride 
(3) Especial informativo

(4) Perfil biográfico u obituario

(5) Previsión informativa

(6) Sección de datos

(7) Repositorios que almacenan cada una de las piezas informativas publicadas acerca de temas, personas, organizaciones y lugares relevantes.

(8) Otros

iv) Función documental específica que cumple el enlace para el conocimiento de la realidad y para la comunicación adecuada siguiendo la propuesta del profesor Galdón (1986 y 1994). Aunque la teoría original fue enunciada como factor del saber periodístico para la tarea concreta de elaborar la información por parte de los periodistas, se ha aplicado en esta investigación adaptándola al conocimiento de la realidad que proporciona el hipertexto a los lectores. Por ello, el número de funciones se ha reducido respecto a la formulación primigenia dejando fuera aquellas que tienen que ver con las tareas previsorias o preparatorias de la información por parte de los redactores y que, obviamente, no pueden ser examinadas a través del hipertexto. Las funciones son:

(1) Crítico-verificadora, que con su dimensión fáctica y crítica pone a disposición de los lectores la información pertinente sobre las fuentes y los temas tratados para que puedan comprobar su fiabilidad, exactitud y veracidad. Es la función que busca evitar la falsedad. En el análisis de contenido se distinguen dos subfunciones:

(2) Crítico-verificadora personal cuando remite a afirmaciones de personalidades.

(3) Crítico-verificadora documental cuando remite a fuentes documentales para demostrar los hechos. 
v) Completiva, que busca los antecedentes y relaciones necesarias para completar la mera información de actualidad. Contribuye a alejarse de la superficialidad. En el análisis se distinguen dos subfunciones:

(1) Completiva con antecedentes.

(2) Completiva con contexto.

vi) Informativa propia, cuando difunde directamente algún producto de índole documental de los enunciados en la variable c. "Estos tipos de información documentada no se pueden insertar dentro de las clasificaciones al uso formuladas en los libros de texto de redacción periodística (...); rompen los moldes informativos del objetivismo y manifiestan la enorme riqueza creativa que tiene el uso inteligente de la documentación en la información periodística" (Galdón, 1994: 193).

vii) Ilustrativa ${ }^{1}$, donde se aprovecha la multimedialidad del periodismo digital para enriquecer el mensaje.

\section{Resultados y discusión}

Para la exposición de los datos se han tenido en cuenta los condicionantes de las unidades de análisis y se ha optado por una presentación mediante valores absolutos que permite describir y percibir la evolución del hipertexto en la prensa española para dar respuesta al objetivo principal de esta investigación descriptivo-retrospectiva. La homogeneización de datos necesaria para realizar comparativas se ha conseguido utilizando porcentajes y no medias, ya que la desviación estándar entre las unidades de análisis es muy alta y no permite llegar a conclusiones científicamente válidas.

\subsection{Destino del enlace: interno o externo}

El porcentaje de enlaces internos es abrumador y coincidente con lo que indicaban las investigaciones previas (Diezhandino, 2008; Fondevila Gascón; 2012 y 2013; Arias Robles, 2015). El número de enlaces internos continúa siendo desmesurado en todas las publicaciones. El Mundo, Las Provincias y 
Levante tienen cifras superiores al 90\%, y en El País tres de cada cuatro enlaces que aparecen en el texto de la información son internos. Los dos medios nativos digitales son los que mayor uso efectúan de los enlaces externos, que se aproximan al 35\% del total. En cualquier caso, todos los medios practican una estrategia informativa autorreferencial.

Gráfico-tabla 1: Destino de los enlaces incluidos en el relato informativo
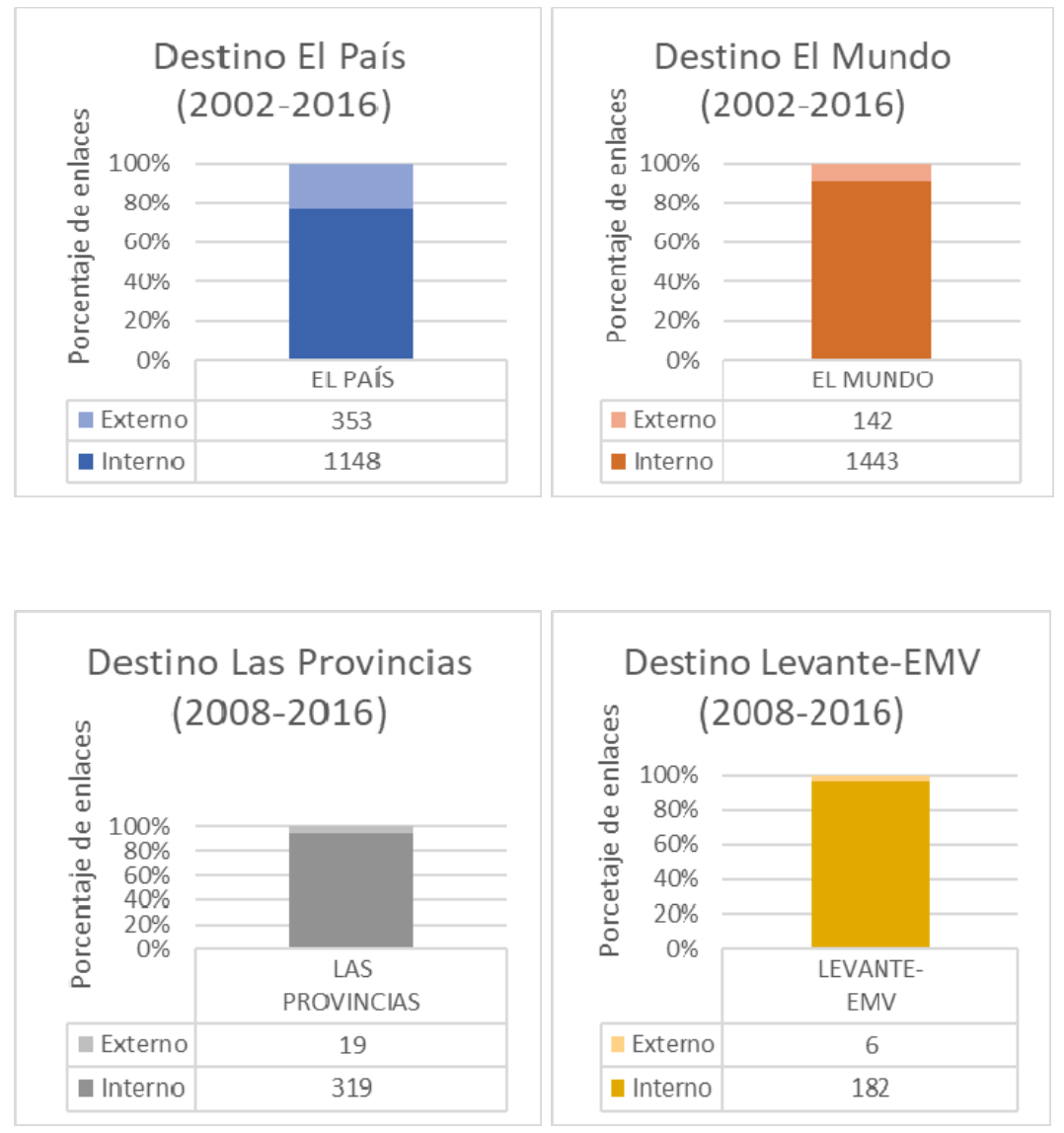


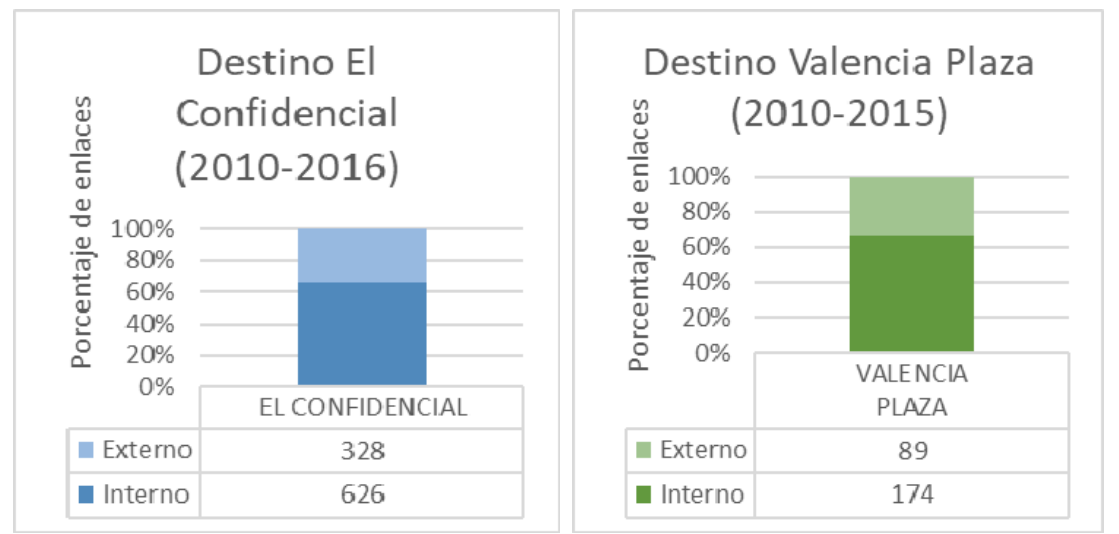

3.2. Categoría documental del nodo de destino

\subsubsection{Género periodístico o documental del nodo de destino}

Tal y como cabe esperar, en todos los diarios son minoritarios los nodos de destino que remiten a piezas de carácter documental, especialmente en los medios locales o en los nativos digitales con valores que oscilan entre el 9 y el 23\%. El País y El Mundo son las dos cabeceras que más utilizan los géneros documentales en los nodos de destino con porcentajes del 38\% y del 30\% respectivamente.

Gráfico-tabla 2: Tipología del género de los enlaces incluidos en el relato informativo 


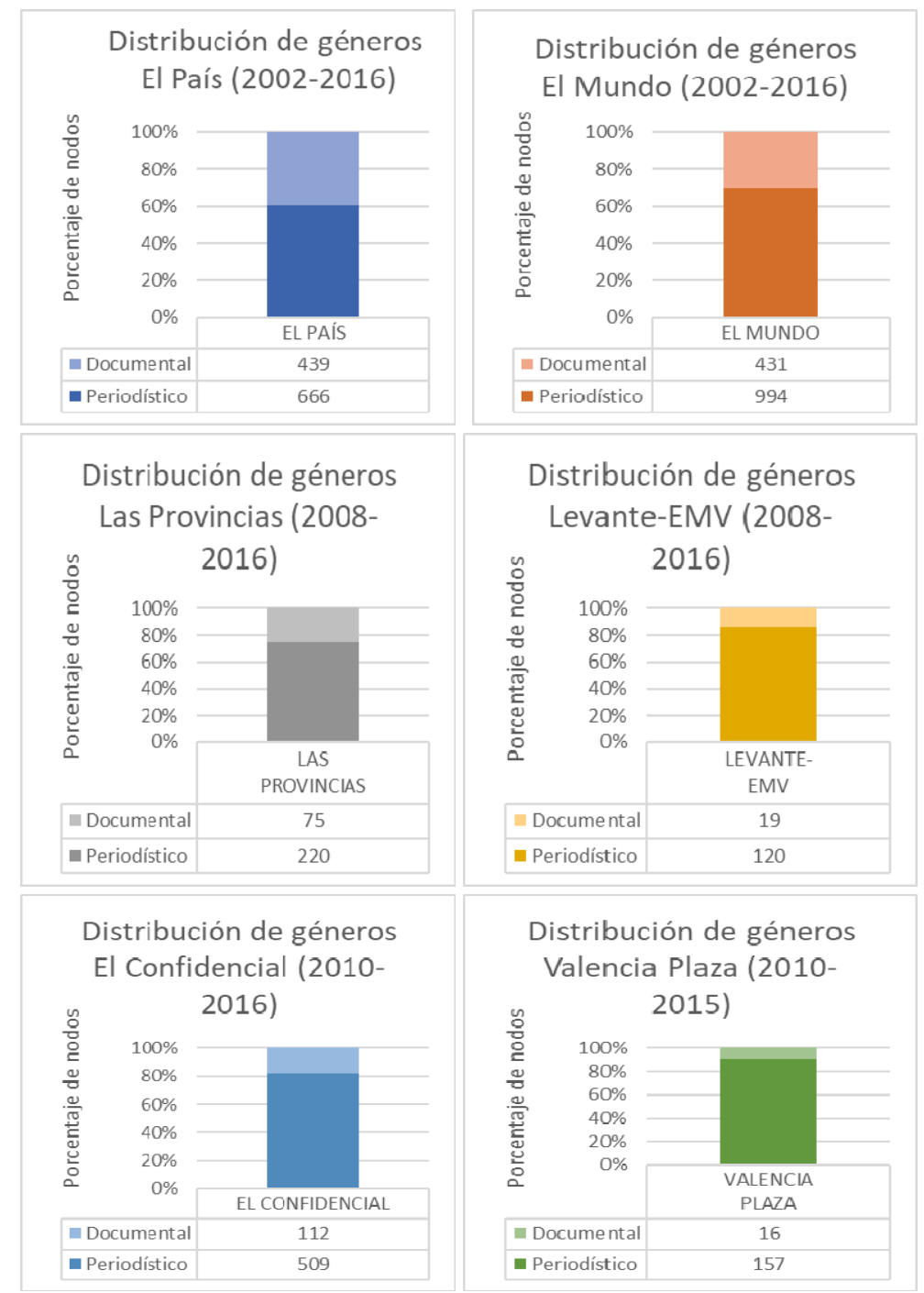

\subsubsection{Evolución cronológica del uso del género documental en los nodos de destino. Evolución cronológica (2010-2015)}

La evolución cronológica del uso de los géneros documentales muestra en general un comportamiento irregular. En los tres medios nacionales el crecimiento ha sido constante a lo largo de los años, pero como veremos 
posteriormente, el aumento se explica por la aparición de los repositorios temáticos y no por el empleo de productos documentales clásicos. En los diarios locales el uso de nodos de carácter documental ha ido descendiendo con los años o tiene un comportamiento errático.

\section{Gráfico-tabla 3: Evolución cronológica de piezas con género documental en los nodos de destino en valores porcentuales}

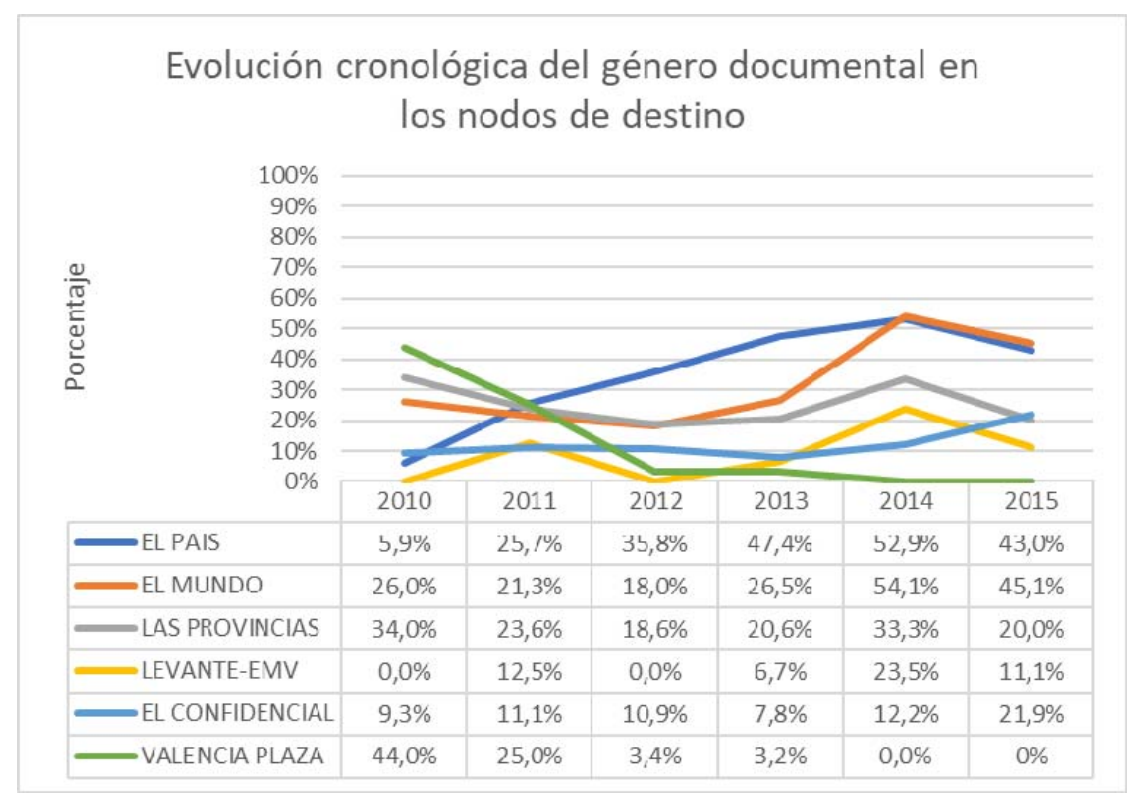

\subsubsection{Tipología de destino}

Si excluimos al propio diario como destino mayoritario de los enlaces, las webs institucionales y otros medios de comunicación son las fuentes más frecuentes a las que remiten los vínculos. El resto de destinos: blogs, redes sociales, webs personales u otro tipo de recursos tienen valores prácticamente nulos.

Los periódicos se comportan de manera similar según las parejas que hemos establecido para las comparativas y que tienen períodos de análisis idénticos. El País y El Mundo recurren como segunda fuente de destino a las webs 
institucionales y resulta destacado que no utilizan recursos de medios de su mismo grupo de comunicación, aunque sean mayoritariamente medios audiovisuales. Las Provincias y Levante-EMV sí que hacen mayor uso del resto de cabeceras que pertenecen a sus grupos de prensa. Finalmente, en El Confidencial y Valencia Plaza los destinos externos más frecuentados son las webs institucionales y los medios de comunicación ajenos.

Tabla 2: Tipología de los nodos de destino de los enlaces incluidos en el relato informativo en valores porcentuales

\begin{tabular}{|c|c|c|c|c|c|c|}
\hline & El País & $\begin{array}{c}\text { El } \\
\text { Mundo }\end{array}$ & $\begin{array}{c}\text { Las } \\
\text { Provinc. }\end{array}$ & $\begin{array}{c}\text { Levante- } \\
\text { EMV }\end{array}$ & $\begin{array}{c}\text { El } \\
\text { Confiden. }\end{array}$ & $\begin{array}{c}\text { Valencia } \\
\text { Plaza }\end{array}$ \\
\hline $\begin{array}{l}\text { Propio } \\
\text { medio }\end{array}$ & 75,5 & 91 & 94,4 & 96,3 & 67,6 & 66,2 \\
\hline Blog & 1,1 & 0,1 & 0 & 0 & 1,3 & 2,3 \\
\hline $\begin{array}{c}\text { Medio } \\
\text { ajeno }\end{array}$ & 3,6 & 1,3 & 0,6 & 0 & 8,2 & 8,7 \\
\hline $\begin{array}{l}\text { Medio del } \\
\text { grupo }\end{array}$ & 0 & 0,3 & 2,6 & 4,7 & 0 & 0 \\
\hline $\begin{array}{c}\text { Redes } \\
\text { sociales }\end{array}$ & 2,1 & 1,1 & 0 & 1,1 & 2,5 & 1,5 \\
\hline $\begin{array}{c}\text { Web } \\
\text { institucio } \\
\text { nal }\end{array}$ & 16,1 & 5,9 & 4,1 & 1,6 & 19,6 & 20,5 \\
\hline $\begin{array}{c}\text { Web } \\
\text { personal }\end{array}$ & 0,3 & 0,3 & 0 & 0 & 0,7 & 0,8 \\
\hline Otras & 0,3 & 0,1 & 0 & 0 & 0,1 & 0 \\
\hline
\end{tabular}

\subsubsection{Género documental de los nodos de destino por medios}

Dado que no se aprecia una pauta común entre medios sobre los géneros documentales de los nodos de destino en los enlaces incluidos en el cuerpo de las informaciones, se ha optado por hacer una explicación individualizada por medios. 
Casi el 85\% de los nodos de destino con carácter documental en El País son repositorios temáticos. El resto de productos documentales son casi inexistentes. El crecimiento de los géneros documentales en los últimos años que se ha observado en la gráfica-tabla 3 se explica por el uso creciente y masivo de estos repositorios y no por los productos documentales clásicos.

El Mundo ha utilizado en los nodos de destino, a lo largo del periodo analizado, tres tipos de productos documentales en la misma proporción: especiales, perfiles biográficos y repositorios temáticos. Sin embargo, si tenemos en cuenta que la introducción de los repositorios es muy reciente, de 2014, no cabe duda de que estos almacenes de noticias son el producto documental más usado en la actualidad en detrimento del resto de géneros documentales, y que el peso de especiales y perfiles biográficos ha ido decayendo con el tiempo. En el caso de los perfiles biográficos, el 75\% de ellos llevan la firma de algún redactor o la genérica del propio medio, y solo el $25 \%$ provienen de agencias.

En el diario Las Provincias la mayor parte de los nodos de destino que pertenecen al género documental son perfiles biográficos, el 41,3\% de los casos. Sin embargo, solo el 35\% están elaborados en el propio diario, ya que la mayor parte de ellos, el 65\%, vienen firmados por agencias de prensa.

Por otro lado, aunque Las Provincias utiliza en abundancia las etiquetas temáticas que remiten a repositorios, el uso de estos repositorios se limita a los tags, que se sugieren en el exterior de las informaciones, y no se aprovecha los enlaces incluidos en el interior de las noticias para remitir a ellos.

En el caso del diario Levante-EMV los dos géneros documentales que más se enlazan, y en la misma proporción, son los especiales y los perfiles biográficos. La autoría de estos últimos es de agencias en el 60\% de los casos.

En El Confidencial el género documental mayoritario de los nodos de destino son los repositorios temáticos con un porcentaje muy elevado, el 62,5\%. Le 
siguen los perfiles biográficos y en un porcentaje muy próximo las secciones de datos, un producto inapreciable en el resto de medios analizados.

En Valencia Plaza el uso de géneros documentales es minoritario. Solo el 12,5 de los nodos de destino que tienen un carácter documental son perfiles biográficos y la misma cantidad remite a secciones de datos. Este dato coincide con El Confidencial. Los dos diarios nativos digitales son los que emplean mayores enlaces hacia este tipo de secciones.

El 75\% de los productos documentales en Valencia Plaza está clasificado en la categoría de "otros" y en concreto son informes en PDF de fuentes institucionales que han sido alojados en la web del periódico para que los lectores puedan consultarlos íntegramente. Esta fue una práctica habitual hasta el año 2012 que fue desapareciendo paulatinamente.

Tabla 3: Género documental de los nodos de destino en valores absolutos

\begin{tabular}{|c|c|c|c|c|c|c|}
\hline & E1 País & E1 Mundo & $\begin{array}{c}\text { Las } \\
\text { Provinc. }\end{array}$ & $\begin{array}{c}\text { Levante- } \\
\text { EMV }\end{array}$ & $\begin{array}{c}\text { El } \\
\text { Confidenc. }\end{array}$ & $\begin{array}{c}\text { Valencia } \\
\text { Plaza }\end{array}$ \\
\hline Cronología & 0 & 12 & 6 & 2 & 2 & 0 \\
\hline Efemérides & 5 & 9 & 1 & 1 & 1 & 0 \\
\hline Especiales & 8 & 132 & 9 & 5 & 2 & 0 \\
\hline $\begin{array}{c}\text { Perfil } \\
\text { biográfico u } \\
\text { obituarios }\end{array}$ & 35 & 128 & 31 & 5 & 13 & 2 \\
\hline $\begin{array}{l}\text { Previsiones } \\
\text { informativas }\end{array}$ & 0 & 3 & 1 & 0 & 1 & 0 \\
\hline $\begin{array}{l}\text { Secciones } \\
\text { datos }\end{array}$ & 6 & 12 & 1 & 3 & 10 & 2 \\
\hline Temas & 372 & 117 & 14 & 2 & 70 & 0 \\
\hline Otros & 13 & 18 & 12 & 1 & 13 & 12 \\
\hline TOTAL & 439 & 431 & 75 & 19 & 112 & 16 \\
\hline
\end{tabular}


A continuación, ofrecemos una tabla con las cifras absolutas para el período establecido en cada cabecera. Las comparativas deben realizarse con rigor observando los pares de columnas (medios nacionales, medios locales, nativos digitales).

Tanto El País como El Mundo presentan en el período 2002-2016 un número prácticamente idéntico de hipervínculos en el cuerpo de la noticia que remiten a géneros documentales (439 y 431, respectivamente). Sin embargo, El Mundo muestra una mayor variedad de géneros documentales clásicos, mientras que El País, por el contrario, se concentra en los repositorios temáticos.

En el caso de los diarios valencianos con tradición en papel y para el período 2008-2016, Las Provincias dirige a sus lectores en una proporción mucho más elevada a piezas documentales de lo que lo hace Levante-EMV. El primer diario llega a cuadruplicar en valores al segundo ( 84 y 19, respectivamente).

Finalmente, en los nativos digitales, en el período 2010-2015, las diferencias también son abismales cuantitativamente y en variedad de géneros. Valencia Plaza apenas envía a sus lectores a piezas de carácter documental en los enlaces insertados en el relato informativo.

\subsection{Función documental de los enlaces por medios ${ }^{2}$}

Para concluir este epígrafe de resultados, se expone la función documental que cumple el nodo de destino dentro del relato informativo. Esta labor del enlace ha sido evaluada en todos los vínculos que aparecen en el cuerpo de las noticias, independientemente de su destino y de que esta función sea más o menos intencionada. La comparativa entre medios puede realizarse con rigor observando la siguiente tabla por pares de columnas, ya que recogen los medios con idéntico período de análisis: 
Tabla 4: Función documental de los enlaces por medios en valores absolutos

\begin{tabular}{|c|c|c|c|c|c|c|}
\hline & El País & El Mundo & $\begin{array}{c}\text { Las } \\
\text { Provincias }\end{array}$ & $\begin{array}{c}\text { Levante- } \\
\text { EMV }\end{array}$ & $\begin{array}{c}\text { El } \\
\text { Confidenc. }\end{array}$ & $\begin{array}{c}\text { Valencia } \\
\text { Plaza }\end{array}$ \\
\hline $\begin{array}{l}\text { Completiva } \\
\text { antecedente }\end{array}$ & 249 & 424 & 72 & 33 & 231 & 27 \\
\hline $\begin{array}{c}\text { Completiva } \\
\text { contexto }\end{array}$ & 337 & 388 & 81 & 55 & 265 & 101 \\
\hline $\begin{array}{c}\text { Crítico } \\
\text { verificadora: } \\
\text { documental }\end{array}$ & 262 & 170 & 24 & 12 & 202 & 90 \\
\hline $\begin{array}{c}\text { Crítico } \\
\text { verificadora: } \\
\text { personal }\end{array}$ & 81 & 120 & 20 & 7 & 50 & 22 \\
\hline Ilustrativa & 20 & 30 & 40 & 19 & 15 & 11 \\
\hline $\begin{array}{c}\text { Informativa } \\
\text { propia }\end{array}$ & 458 & 414 & 75 & 18 & 114 & 3 \\
\hline
\end{tabular}

Todas las funciones documentales están presentes en los nodos de destino. La función completiva, sea de antecedente o de contexto, es la predominante en todas las cabeceras, entre el 50 y $60 \%$ del total.

En lo referente a la función crítico-verificadora, se detecta una tendencia que destaca en los diarios nativos digitales, con menos trayectoria, respecto al resto: El Confidencial con 28,7\% y Valencia Plaza con 44,1\%. Los medios nacionales tradicionales obtienen valores equilibrados y próximos (El País, 24,4\%, y El Mundo, 19\%). Los diarios locales con edición en papel son los que ofrecen resultados más bajos en la verificación: Las Provincias, 14,1\%, y Levante, $13,2 \%$.

La función informativa propia, la que equivale al uso de productos documentales, alcanza entre el 25 y $30 \%$ en El País, El Mundo y Las 
Provincias. En el caso de El País y Las Provincias, como hemos visto en el epígrafe anterior, a causa del mayor uso de los repositorios temáticos; y en El Mundo por la variedad de géneros documentales tradicionales que emplea.

Aunque el carácter multimedia es una de las notas características del periodismo digital, se desaprovecha el uso de enlaces con función ilustradora. Es ínfimo en todas las cabeceras, con la excepción de Las Provincias (12,8\%) y Levante $(13,2 \%)$. Las fotografías y vídeos se insertan en el cuerpo de la información y se reproducen en el interior de la propia noticia, siendo poco frecuente que se remita a otros nodos ajenos a la noticia que incluyan galerías de imágenes o vídeos más extensas.

Gráfico-tabla 4: E1 País: función documental de los enlaces por medios en términos porcentuales

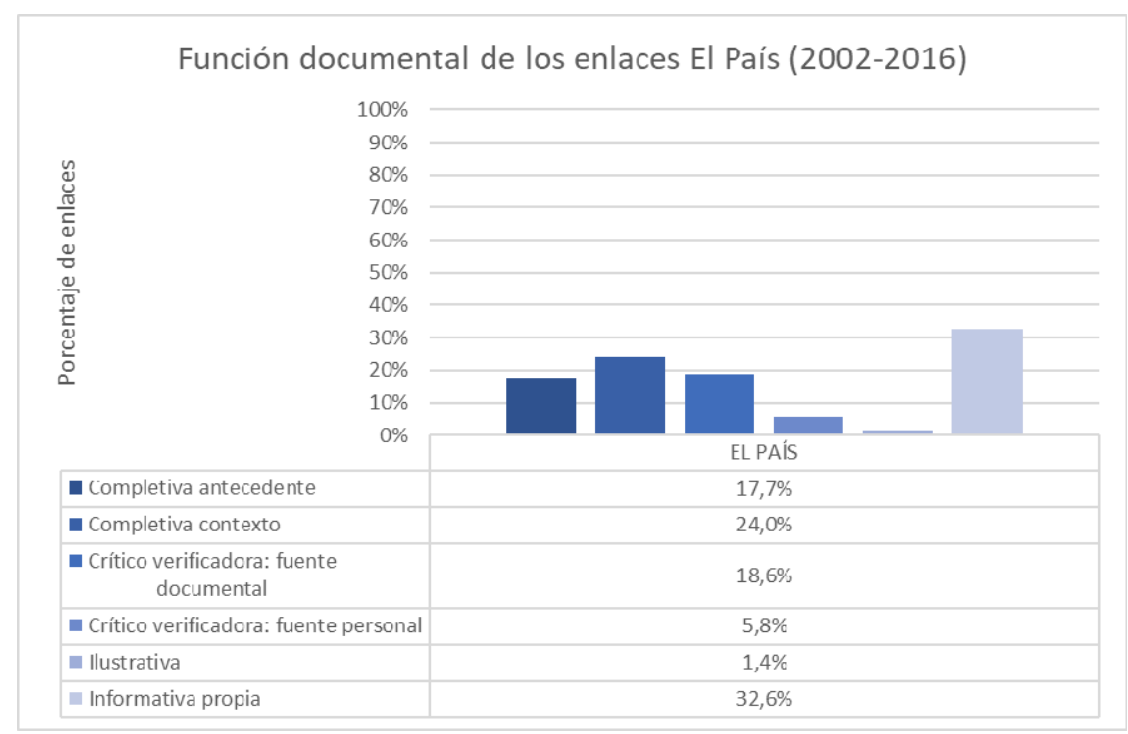


Gráfico-tabla 5: El Mundo: función documental de los enlaces por medios en términos porcentuales

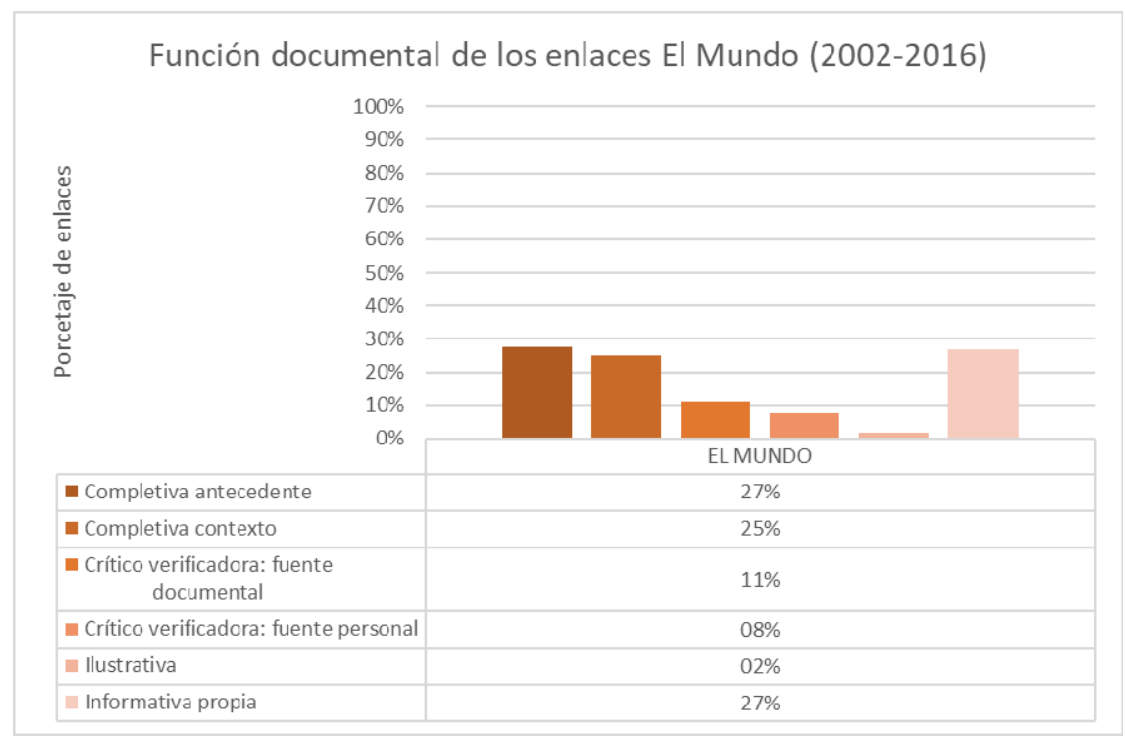

Gráfico-tabla 6: Las Provincias: función documental de los enlaces por medios en términos porcentuales

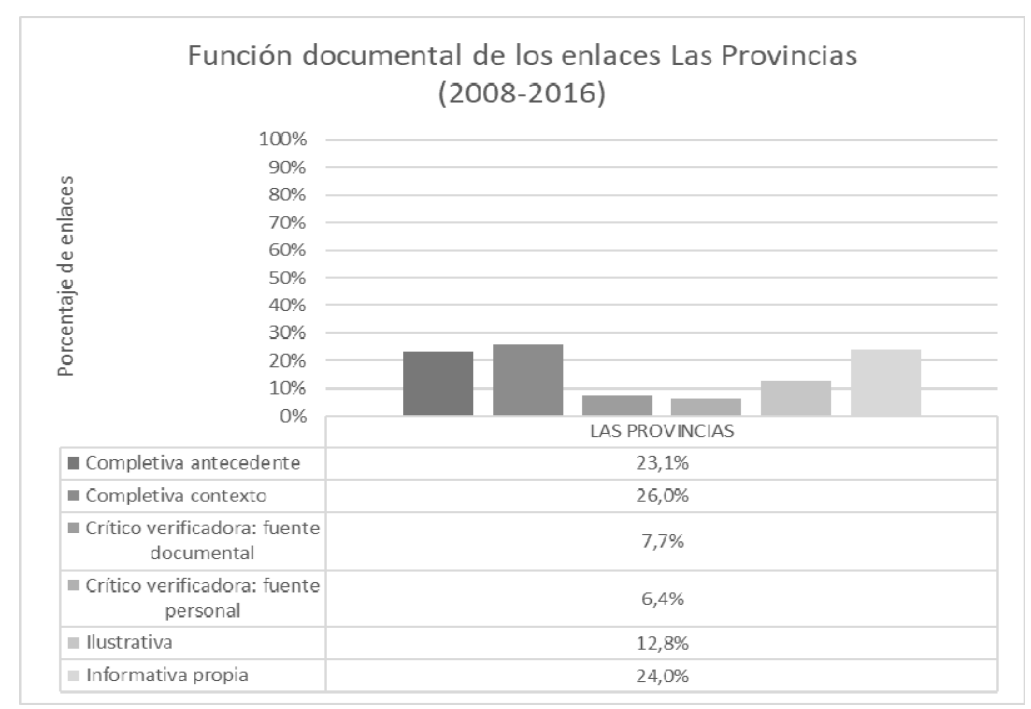


Gráfico-tabla 7: Levante-EMV: función documental de los enlaces por medios en términos porcentuales

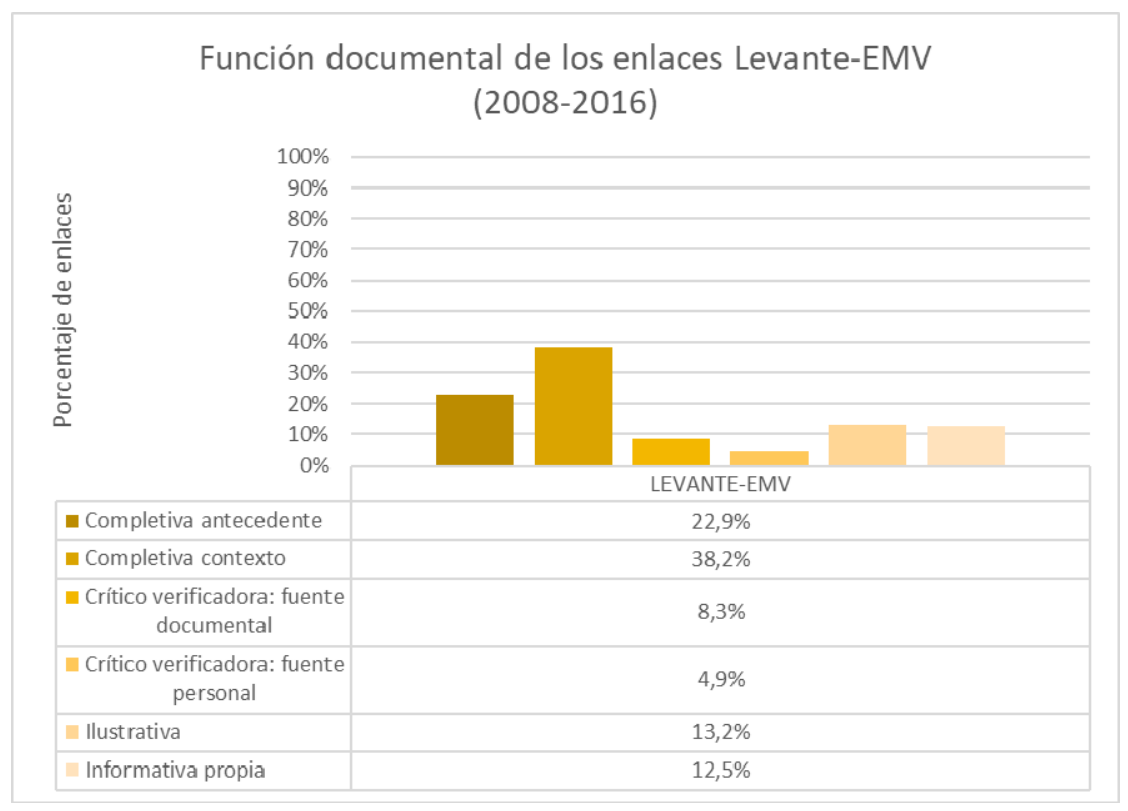

Gráfico-tabla 8: El Confidencial: función documental de los enlaces por medios en términos porcentuales

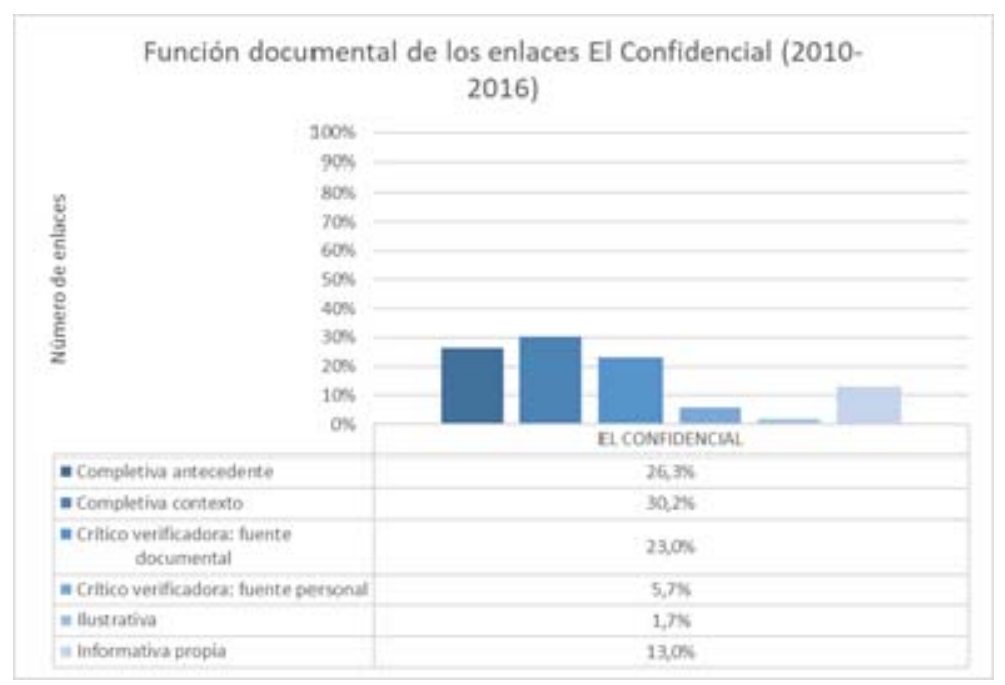


Gráfico-tabla 9: Valencia Plaza: función documental de los enlaces por medios en términos porcentuales

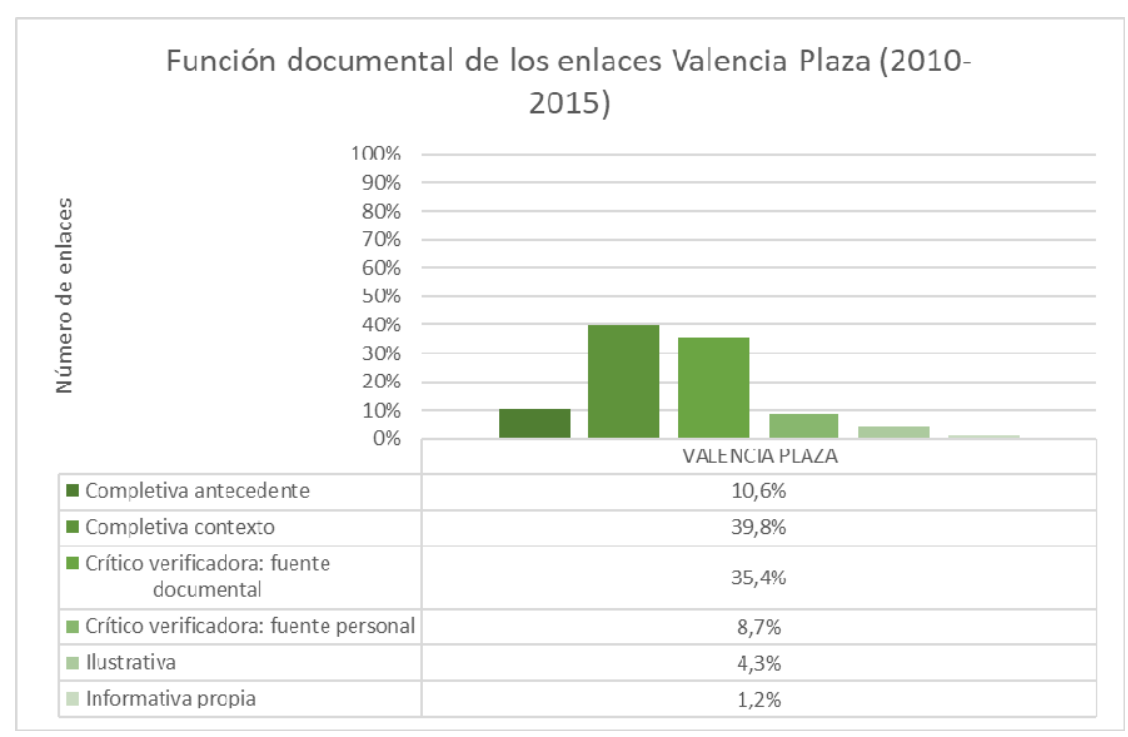

\section{Conclusiones}

Los medios siguen practicando una política autorreferencial respecto al uso del hipertexto, que, si bien es cierto, no es dañina y pone en valor la trayectoria del diario y su fondo documental, apenas deja margen para ofrecer los recursos valiosos de la red que se presuponían en la primera de las hipótesis. Los medios nativos digitales analizados son los que muestran una mayor apertura hacia el exterior. El intento de que el lector permanezca el mayor tiempo posible dentro de la publicación navegando entre páginas propias y de que no se marche a recursos externos explica esta política restrictiva de destino y que no aprovecha una de las ventajas inherentes de internet en el periodismo digital: proporcionar al lector una documentación rica y sin límites.

Tampoco se confirma la segunda hipótesis: no hay una evolución de la tipología de los destinos de los enlaces externos (redes sociales, blogs, etc.), 
sino que se constata una continuidad de los recursos de siempre (webs institucionales y de otros medios de comunicación).

El uso de los géneros documentales ha sido errático en la prensa española en el último lustro. La observación detallada muestra más bien el empobrecimiento sugerido en la tercera hipótesis. Aunque en los tres medios nacionales estudiados el crecimiento ha sido constante a lo largo de los años, este aumento se explica por la aparición de los repositorios temáticos y no por el empleo de productos documentales clásicos. Y en los diarios locales el uso de nodos de carácter documental ha ido descendiendo con los años o tiene un comportamiento variable.

Las funciones clásicas documentales sí están presentes en los nodos de destino de los enlaces, como se aventuraba en la cuarta hipótesis, siendo la completiva (de antecedente o contexto) la más utilizada. La informativa propia, la que acoge a los géneros documentales, ocupa también un lugar muy destacado en la mayor parte de los medios analizados. Sin embargo, como se ha apuntado antes, hay que matizar que no se debe a un crecimiento de los géneros tradicionales, sino al uso de estos repositorios temáticos. Los vínculos al resto de productos documentales son mínimos y solo se mantienen los perfiles biográficos, aunque mayoritariamente provienen de agencias. Que los enlaces no remitan a piezas propiamente documentales es consecuencia de que o bien los géneros documentales clásicos han desaparecido de la prensa sin aprovechar la potencialidad del mundo digital; de que, si existen, se desaprovechan al no mostrarlos al lector en el relato informativo; o, incluso, de ambas circunstancias.

El uso de los repositorios temáticos como nodo de destino de los hipervínculos incluidos en cuerpo de las noticias no proviene de la tarea crítica de evaluación de las noticias publicadas con anterioridad o de los recursos de internet que pueden resultar más pertinentes para el lector justo en ese instante de la narración periodística, sino que responde a motivaciones SEO y de 
número de visitas. Esta práctica, sobre todo en temas o personalidades destacadas o recurrentes en la actualidad, no contribuye a ofrecer información precisa y conocimiento en la lectura de la noticia, sino que más bien causa dispersión, fragmentación y vaguedad en la navegación, mucho más si tenemos en cuenta que estos "almacenes de noticias" tienen una organización basada únicamente en criterios cronológicos y no permiten ningún filtro de búsqueda o presentación de resultados. Paradójicamente, con este uso, los hipervínculos del cuerpo no cumplen con la misión periodística de orientar, explicar y ofrecer profundidad, sino que potencian una sobreinformación fragmentada.

En síntesis, el uso documental del hipertexto es satisfactorio, aunque hay amplio margen de mejora en el aprovechamiento de la potencialidad de internet. La falta de asentamiento e inmadurez que se observa en otros aspectos del ciberperiodismo (modelo de negocio, narrativas, etcétera) se detecta también en el objeto de estudio.

Después de 20 años de periodismo digital en España, los datos obtenidos en esta investigación invitan a innovar sin perder los rasgos esenciales del periodismo de calidad. ¿Cómo? Redescubriendo el uso inteligente de enlaces en los relatos informativos y desarrollando la potencialidad documental del hipertexto.

\section{Bibliografía}

Abadal, E. y Guallar, J. (2010). Prensa digital y bibliotecas. Gijón: Trea.

Arias Robles, F. (2015). El hipertexto periodístico. influencia del enlace en el mensaje, el emisor y el receptor de información. [Tesis doctoral]. 
Codina, L. (2003). Hiperdocumentos: Composición, estructura y evaluación. En J. Díaz Noci y R. Salaverría (Eds.), Manual de redacción ciberperiodística (pp. 141-194). Barcelona: Ariel.

Diezhandino Nieto, M. P. (2008). Periodismo en la era de Internet: Claves para entender la situación actual de la información periodística en España. Barcelona: Ariel.

Fondevila i Gascón, Joan Francesc (2011). Aplicación semántica de la hipertextualidad en la prensa digital en España. La investigación en periodismo digital: Algunos trabajos desde el ámbito universitario, 169-180.

Fondevila Gascón, J. F. y Segura Jiménez, H. (2012b). El peso de la hipertextualidad en el periodismo digital: estudio comparativo. Cuadernos de Información, 30, 31-40.

Fondevila Gascón, J. F., Beriain Bañares, A. y Olmo Arriaga, del J. L. (2013). Hipertexto, multimedia e interactividad: Comparativa empírica en el periodismo digital español. Breaking the Media Value Chain. VII International Conference on Communication and Reality. Barcelona: Universitat Ramon Llull, 41-50.

Fondevila Gascón, J. F. (2014). El uso de hipertexto, multimedia e interactividad en periodismo digital: Propuesta metodológica de ranking de calidad. Zer: Revista de Estudios de Comunicacion, 19 (36).

Galdón López, G. (1986). El servicio de documentación de prensa: Funciones y métodos. Barcelona: Mitre.

Galdón López, G. (1994). Desinformación. método, aspectos y soluciones. Pamplona: Universidad de Navarra-EUNSA. 
Galdón López, G. (2002). Teoría y práctica de la documentación informativa. Barcelona: Ariel.

García de Torres, E. y Pou Amérigo, M. J. (2003). Características de la comunicación digital. En J. Díaz Noci y R. Salaverría (Eds.), Manual de redacción ciberperiodística (pp. 49-80). Barcelona: Ariel.

Giménez Toledo, E. (2007). Manual de documentación para comunicadores. Pamplona: Eunsa.

Guallar, J. (2011). La documentación en la prensa digital. nuevas tendencias y perspectivas. III Congreso Internacional de Ciberperiodismo y Web 2.0, 52 68.

Igartua Perosanz, J. J. (2006). Métodos cuantitativos de investigación en comunicación. Barcelona: Bosch.

Larrondo, A. (2005). Estructura discursiva de la noticia hipertextual: El valor de la información relacionada y documentada. Ámbitos: Revista Andaluza De Comunicación, (13-14), 155-175.

Murray, R., y Larry, J. (2009). Estadística. México DF: Mc Graw-Hill.

Orero, P., y Cebrián-Enrique, B.J. (2014). Criterios de evaluación y de aplicación de fuentes de información web en centros de documentación periodística. El profesional de la información, 6 (23), pp. 612-617.

Pérez Marco, S. (2004). El concepto de hipertexto en el periodismo digital: Análisis de la aplicación del hipertexto en la estructuración de las noticias de las ediciones digitales de tres periódicos españoles (www.elpais.es, www.elmundo.es, www.abc.es). [Tesis doctoral]. Universidad Complutense de 
Madrid. Facultad de Ciencias de la Información. Recuperada de: http:/ / eprints.ucm.es/tesis/inf/ucm-t26795.pdf.

Rubio Lacoba, M. (2007). Documentación informativa en el periodismo digital. Madrid: Síntesis.

Salaverría, R., Cores, R., Díaz-Noci, J., Meso-Ayerdi, K., y Larrondo, A. (2004). Evaluación de los ciberdiarios en las comunidades vasca y navarra. Comunicación y Sociedad, 17 (1), 161-189.

Sánchez Aranda, J. J. (2005). Análisis de contenido cuatitativo de medios. En M. R. Berganza Conde y J. A Ruiz (Eds.), Investigar en comunicación (pp. 207-228). Madrid: McGraw-Hill.

\section{Notas}

1 Esta función no fue expuesta por Galdón, sino que es una aportación de Elea Giménez (2007: 37) dentro de la función informativa para los medios audiovisuales. Sin embargo, se ha considerado interesante incorporarla por el contexto multimedia y digital del objeto de estudio

2 Los enlaces que remiten a nodos erróneos no están incluidos en los resultados presentados puesto que como es obvio no ha podido determinarse la función documental que cumplían.

\section{Financiación}

Este trabajo se enmarca en un proyecto de investigación del que es miembro Bernardino Cebrián: “Oportunidades y retos del periodismo en los entornos abiertos: Estudio de las voces de la sociedad en torno a los medios tradicionales y los sitios participativos de nueva generación" (Ministerio de Economía y Competitividad, referencia: CSO2016-80703-R / Fondos Feder). 


\section{(c) (1) () ( ) \\ Licencia Creative Commons}

Miguel Hernández Communication Journal mhjournal.org

\section{Cómo citar este texto:}

Bernardino J. Cebrián Enrique y Paz Orero (2017): "Función y valor documental de los enlaces semánticos en la prensa española (2002-2016)", en Miguel Hernández Communication Journal, nº, pp. 489 a 519. Universidad Miguel Hernández, UMH (ElcheAlicante). Recuperado el $\_$de de 20_ de: Џink del artículo en mhjournal.org] 